\title{
Laproscopic evaluation in primary female infertility
}

\author{
Ruby Bhatia ${ }^{1}$, Paramjit Kaur ${ }^{2}$, Gurpinder Kaur ${ }^{3}$, Sunita Mor ${ }^{1 *}$
}

\author{
${ }^{1}$ Department of Obstetrics and Gynecology, MMIMSR, Mullana, Ambala, India \\ ${ }^{2}$ Department of Obstetrics and Gynecology, GMC, Patiala, Punjab, India \\ ${ }^{3}$ Department of Obstetrics and Gynaecology, Private practitioner, Punjab, India
}

Received: 05 August 2019

Accepted: 05 September 2019

\section{*Correspondence:}

Dr. Sunita Mor,

E-mail: drsunita.mor@gmail.com

Copyright: () the author(s), publisher and licensee Medip Academy. This is an open-access article distributed under the terms of the Creative Commons Attribution Non-Commercial License, which permits unrestricted non-commercial use, distribution, and reproduction in any medium, provided the original work is properly cited.

\section{ABSTRACT}

Background: Infertility is defined as inability to conceive within one or more years of regular unprotected coitus. Infertility has now a days not only a medical but a social problem as well. Ignorance and illiteracy, coupled with hesitancy to discuss the problem, complicates the matter further. WHO has listed infertility as a global health issue.

Methods: The present study was conducted on 64 patients with female factor primary infertility admitted in department of obstetrics and gynecology at Rajendra Hospital, Patiala over a duration of 1 year (December 2013November 2014). All the patients had normal semen study of their partner.

Results: In our study mean age was $27.87 \pm 4.57$. No patient was above 40 years of age. Duration of infertility between 1-5 years was in 47 patients $(73.43 \%)$, nine patients $(14.06 \%)$ were infertile for 6-10 years. Out of 64 patients of primary infertility, majority of patients were of endometriosis $15(23.43 \%)$, followed by pelvic inflammatory disease $14(21.87 \%)$, tubal blockade in $7(10.9 \%)$, PCOD in $6(9.37 \%) .14 .08 \%$ patients had normal laproscopic study. 34 patients $(53.12 \%)$ had bilateral spill while no spill was seen in 12 patients $(18.75 \%)$. Unilateral spill was seen in seven patients $(10.93 \%)$ while six patients $(9.37 \%)$ had delayed spill.

Conclusions: Prevalence of infertility is increasing, so is the awareness and treatment seeking behavior. The present study assures that in evaluation and workup of primary infertility patients, after baseline noninvasive investigations, endometrial sampling and HSG, the diagnostic and operative laproscopy is an excellent tool for evaluation of tubal factor. Least expected conditions like endometriosis on clinical evaluation, can be diagnosed and treated with ease on laproscopy. Although tubal factor has been considered to be responsible for a large percentage of cases with female secondary infertility since decades, but in present study laproscopic evaluation confirmed tubal factor in $85.01 \%$ cases with female factor infertility.

Keywords: Endometriosis, Infertility, Laproscopy, Female factor infertility, PCOD, Tubal factor

\section{INTRODUCTION}

Infertility is defined as inability to conceive within one or more years of regular unprotected coitus. ${ }^{1}$ Infertility has now a days not only a medical but a social problem as well. ${ }^{2}$ Ignorance and illiteracy, coupled with hesitancy to discuss the problem, complicates the matter further. ${ }^{3}$ WHO has listed infertility as a global health issue. Dr. Mahmoud Fathalla in his opening remarks at WHO international meeting argued that a major millennium development challenge will be to make management of infertility more accessible to the estimated 80 million couple in world who are unable to conceive. ${ }^{4}$

Infertility is classified into two types.

Primary infertility: in which no previous pregnancy has occurred. 
Secondary infertility: in which a prior pregnancy, although not necessarily a live birth, has occurred, including ectopic gestation. ${ }^{5}$

The incidence of infertility in any community varies between $5 \%$ and $15 \%$. Both partners in relationship contribute to potential infertility and both may be subfertile. The female factor contribute most (i.e 40-55\%) in the etiology of infertility followed by male factors (i.e $30-40 \%)$, both partners (10\%) and unexplained (10\%). ${ }^{6}$

Female factors. $^{7}$

$\begin{array}{lll}\text { Factor } & = & \text { Incidence } \\ \text { Tubal and peritoneal } & = & 25-35 \% \\ \text { Ovulatory } & = & 15-25 \% \\ \text { Cervical } & = & 3-5 \% \\ \text { Other } & = & 1-5 \%\end{array}$

Any infertile couple should be investigated after one year of regular unprotected exposure with adequate frequency. The interval is however, shortened to 6 months after the age of 35 years of women and 40 years of man. ${ }^{1}$ Any infertility evaluation begins with a complete history and physical examination of both partners. The following six parameters should be assessed as these are responsible in majority of infertility cases.

- Male factor

- Cervical factors

- Endometrial-uterine factor

- Tubal factor

- Peritoneal factor

- Ovulatory factor.

The distribution of different causes varies among centres, partly because of difference in referral population. Also, in a significant number of patients, infertility will have multiple causes, and thus every couple must have a complete evaluation even if one problem area is readily identified. ${ }^{8} \mathrm{~A}$ systematic approach to diagnose pathology requires the careful integration of both invasive and non-invasive tests. ${ }^{9}$ Tubal and peritoneal pathology is among the most common causes of infertility, being primary diagnosis in approximately $30-35 \%$ of both younger as well as older infertile couples. Laproscopy is generally regarded as the definitive test for evaluation of tubal factors. ${ }^{10}$

Laproscopy and chromopertubation is widely considered the gold standard test for investigating tubal patency. Additionally, it allows assessment for chronic pelvic inflammatory disease (peritubal disease and adhesions) and endometriosis. This has led to recommendation by NICE (UK) that women suspected of having comorbidities such as endometriosis and pelvic inflammatory disease should undergo laproscopy so that pelvic and tubal pathology both can be assessed. ${ }^{11}$ The ability to see and manipulate the uterus, fallopian tube and ovaries during laproscopy has made it an essential part of infertility evaluation. ${ }^{12}$
Most importantly, laproscopy offers the opportunity to treat disease at the time of diagnosis. Lysis of flimsy or focal adhesions, excision or ablation of superficial and deep endometriotic implants and ovarian drilling in PCOS are relatively simple procedures well within capabilities of most surgeons. ${ }^{10}$ Laproscopy is a minimally invasive technique that provides a panoramic and magnified view of the pelvic organs. ${ }^{13}$

Laproscopy is basic and necessary current diagnostic method of obtaining real notion for the state of internal genital organs especially for tubal factors in female infertility and furthermore also evaluation for the necessity and possibility of microsurgical reproductive operations. ${ }^{14}$

The objectives of this study were to evaluate causes of primary infertility by diagnostic laproscopy. To visualize tubal morphology and patency by chromopertubation. To study the external surfaces of internal pelvic organs and identify local pathology of uterus, tubes, ovaries, peritubal and periovarian adhesions responsible for infertility by laproscopy. To do minimal operative procedures like adhesiolysis, excision and ablation of endometriotic implants, ovarian drilling and aspiration of fluid from pouch of doughlas for biochemical analysis to diagnose or rule out genital tuberculosis.

\section{METHODS}

The present study was conducted on 64 patients with female factor primary infertility admitted in department of obstetrics and gynecology at Rajendra Hospital, Patiala over duration of 1 year (December 2013-November 2014). All the patients had normal semen study of their partner. All infertility investigation CBC, BT, CT, urine complete examination, serum FSH, LH, AMH, blood sugar, serum prolactin, ESR, chest $\mathrm{X}$ ray, pre-menstrual endometrial sampling were done in all patients. The patients were counseled for the procedure and informed consent was taken after explaining all the complications.

\section{Inclusion criteria}

- Females with primary infertility in age group of 2040 years.

\section{Exclusion criteria}

- Male factor infertility

- Infections

- Severe cardiopulmonary disease

- Haemodynamically unstable patient

- Generalized peritonitis

- Significant haemoperitoneum

- Previous periumblical surgery

- Extreme obesity.

A detailed history, physical examination and laboratory workup was done in all patients, patients were subjected to laproscopy and chromopertubation under general 
anaesthesia in post menstrual phase. A two port approach was used, wherever required, three or more port approach was done.

Pelvic organs were inspected for any evidence of adhesions, PID, endometriosis, PCOD or ovarian cysts, presence of altered blood/ straw coloured fluid. Ablation of endometrial implants and adhesiolysis, ovarian drilling and aspiration of fluid from pouch of doughlas, if any, were performed as per need. Chrompertubation was done for confirmation of tubal patency. The data was collected, compiled and analyzed statistically.

\section{RESULTS}

The present study was carried out in department of obstetrics and gynecology, Government Medical College, Patiala. A total of 64 patients with primary infertility were taken for study. Following observations were made during study.

Table 1: Age distribution in primary infertility.

\begin{tabular}{|lll|}
\hline Age groups (years) & Number of cases & Percentage \\
\hline $20-25$ & 24 & 37.5 \\
\hline $26-30$ & 22 & 34.4 \\
\hline $31-35$ & 14 & 21.9 \\
\hline $36-40$ & 4 & 6.25 \\
\hline$>40$ & 0 & 0 \\
\hline
\end{tabular}

In our study mean age was $27.87 \pm 4.57$. No patient was above 40 years of age. Maximum patients i.e $37.5 \%$ were in age group of 20-25 years (Table 1).

Table 2: Distribution according to duration of primary infertility.

\begin{tabular}{|lll|}
\hline $\begin{array}{l}\text { Duration of infertility } \\
\text { (years) }\end{array}$ & $\begin{array}{l}\text { Number of } \\
\text { cases }\end{array}$ & Percentage \\
\hline $1-5$ & 47 & $73.43 \%$ \\
\hline $6-10$ & 9 & $14.06 \%$ \\
\hline $11-15$ & 5 & $7.81 \%$ \\
\hline$>15$ & 3 & $4.86 \%$ \\
\hline
\end{tabular}

Duration of infertility between 1-5 years was in 47 patients $(73.43 \%)$, nine patients $(14.06 \%)$ were infertile for 6-10 years. Only three patients $(4.86 \%)$ were infertile for $>15$ years (Table 2).

Table 3: Presenting complaints.

\begin{tabular}{|ll|}
\hline Presenting compliant & Percentage \\
\hline Inability to conceive & $64 \%$ \\
\hline Menstrual irregularity & $19 \%$ \\
\hline Congestive Dysmenorrhea & $17 \%$ \\
\hline
\end{tabular}

Primary infertility was the presenting complaint in $64 \%$ women while menstrual irregularity and congestive dysmennorhea were chief complaints in $19 \%$ and $17 \%$ patients respectively (Table 3 ).

Table 4: Laproscopic findings.

\begin{tabular}{|lll|}
\hline Laproscopic finding & $\begin{array}{l}\text { Number } \\
\text { of cases }\end{array}$ & Percentage \\
\hline Normal study & 9 & $14.08 \%$ \\
\hline Endometriosis & 15 & $23.43 \%$ \\
\hline Pelvic inflammatory disease & 14 & $21.87 \%$ \\
\hline Adhesions & 2 & $3.12 \%$ \\
\hline Fibroids & 3 & $4.68 \%$ \\
\hline Pelvic tuberculosis & 3 & $4.68 \%$ \\
\hline Tubal blockade & 7 & $10.9 \%$ \\
\hline PCOS & 6 & $9.37 \%$ \\
\hline Ovarian enlargement & 1 & $1.56 \%$ \\
\hline Hydrosalpinx & 2 & $3.12 \%$ \\
\hline Mullerian anomaly & 2 & $3.12 \%$ \\
\hline
\end{tabular}

Out of 64 patients of primary infertility, majority of patients were of endometriosis $15(23.43 \%)$, followed by pelvic inflammatory disease $14(21.87 \%)$, tubal blockade in $7(10.9 \%)$, PCOD in $6(9.37 \%) .14 .08 \%$ patients had normal laproscopic study (Table 4 ).

Table 5: Chromopertubation findings.

\begin{tabular}{|lll|}
\hline Spill & Number of cases & Percentage \\
\hline Bilateral spill & 34 & $53.12 \%$ \\
\hline Delayed spill & 6 & $9.37 \%$ \\
\hline No spill & 12 & $18.75 \%$ \\
\hline Unilateral spill & 7 & $10.93 \%$ \\
\hline Extravasation of dye & 5 & $7.81 \%$ \\
\hline
\end{tabular}

Out of 64 patients, 34 patients $(53.12 \%)$ had bilateral spill while no spill was seen in 12 patients (18.75\%). Unilateral spill was seen in seven patients $(10.93 \%)$ while six patients $(9.37 \%)$ had delayed spill. Extravasation of dye was seen in five patients $(7.81 \%)$ (Table 5$)$.

Table 6: Operative procedure.

\begin{tabular}{|l|l|l|}
\hline Procedure & $\begin{array}{l}\text { Number } \\
\text { of cases }\end{array}$ & Percentage \\
\hline $\begin{array}{l}\text { Adhesiolysis and ablation of } \\
\text { endometriotic implants }\end{array}$ & 8 & $11.7 \%$ \\
\hline Ovarian drilling & 2 & $3.1 \%$ \\
\hline $\begin{array}{l}\text { Diagnostic aspiration of } \\
\text { fluid from POD }\end{array}$ & 8 & $11.7 \%$ \\
\hline $\begin{array}{l}\text { Cystectomy for } \\
\text { endometrioma with }\end{array}$ & 7 & $10.9 \%$ \\
adhesiolysis & & \\
\hline
\end{tabular}

Adhesiolysis, ablation of endometriotic implants and diagnostic aspiration of fluid from POD was done in eight $(11.7 \%)$ cases each, cystectomy for endometriomas with adhesiolysis was done in seven $(10.9 \%)$ cases and ovarian drilling in two $(3.1 \%)$ cases (Table 6). 


\section{DISCUSSION}

The desire to procreate is a universal phenomenon, both partners have level of potential fertility and it is combination of their potential that determines fertility. Female infertility is a commonly encountered problem that presently accounts for a significant percentage of women seeking gynecological services. Evaluation is the starting point for treatment of infertility as it may suggest specific cause and appropriate treatment modalities. Although history and physical examination provide significant information, specific tests are required to evaluate infertility. Diagnostic laproscopy is normally the standard procedure performed as the final test in infertility work up before progressing to infertility treatment. It is the gold standard in diagnosing tubal pathology and other intraabdominal causes of infertility. Although tubal factor has been considered to be responsible for a large percentage of cases with female secondary infertility since decades, but in present study laproscopic evaluation confirmed pathology in $85.01 \%$ cases with female factor infertility.

In the present study, most cases were in age group of 21 25 years $(37.5 \%)$. In a study by Shamim et al, maximum number of patients were in age group of 26-30 years $(47.4 \%)$, Shetty et al also observed same distribution $(32.35 \%) .{ }^{11,15}$ Kanal et al $(45 \%)$ and Bhatia et al observed maximum cases in age group of $21-25$ years $(49.4 \%){ }^{6,16}$

Bhatia et al $(51.51 \%)$ and Kanal et al (47\%) had maximum patients with 1-5 years of infertility. ${ }^{6,16}$ Shetty et al also observed that most of patients of primary infertility had duration of $1-5$ years $(67.6 \%) .{ }^{11}$ In the present study also duration of infertility was $1-5$ years in $73.53 \%$ cases.

Haider et al, found menstrual irregularity in $45 \%$ cases of primary infertility. ${ }^{17}$ In a study by Aziz et al, $29.1 \%$ patients of primary infertility had menstrual irregularity. ${ }^{18}$ In our study $19 \%$ patients of primary infertility had menstrual irregularity.

In a study by Kanal et al, out of 40 patients studied, 30\% patients had normal laproscopy finding while $70 \%$ had abnormal findings. ${ }^{6}$ Butt et al studied 40 patients and observed normal laproscopic findings in $37.5 \%$ and abnormalities in $62.5 \%$ patients. Haider et al had $6.66 \%$ patients with normal laproscopy findings and $93.3 \%$ with abnormal findings out of 30 patients studied. ${ }^{17,19}$ Shamim et al observed 54 patients out of them $29.6 \%$ patient had normal laproscopic findings and $70.3 \%$ had abnormal finding. ${ }^{15}$ In our study bulk of patients $(85.92 \%)$ had abnormal findings and only $14.08 \%$ patients had normal study on laproscopic evaluation.

Kanal and Sharma did a study of primary infertility in females by diagnostic laproscopy, found tubal blockage in $22.5 \%$ cases, pelvic TB, fibroid, ovarian enlargement and hypoplastic uterus in $5 \%$ each and normal study in
$30 \%{ }^{6}$ Shamim et al observed $22.22 \%$ cases of tubal blockage, $18.5 \%$ with adhesions, $9.25 \%$ of PCOD, $7.4 \%$ each had endometriosis and fibroid, $3.7 \%$ each of hydrosalpinx and mullerian anomalies while $29.6 \%$ patients had normal study. ${ }^{15}$ Butt et al in her study observed tubal blockage in $47.5 \%$ patients, $7.5 \%$ each of adhesions and mullerian anomalies, $2.5 \%$ each of pelvic TB, fibroid and ovarian enlargement while $37.5 \%$ patients had normal study. ${ }^{19}$

In a study by Tsuji et al endometriosis was identified in $63.2 \%$ cases, $8.8 \%$ had adhesions, $10.5 \%$ patients had fibroid, $5.3 \%$ cases had tubal occlusion while $1.8 \%$ cases had ovarian enlargement. ${ }^{20}$ Aziz et al study had majority of patients with tubal occlusion $26 \%$ followed by PCOD in $10 \%$, adhesion and endometriosis in $12 \%$, pelvic inflammatory disease in $8 \%$, fibroid $6 \%$, ovarian enlargement $4 \%$ and normal laproscopy finding in $20 \%$ cases. $^{18}$

Haider et al in her study found endometriosis in $43.33 \%$, tubal blockage in $16.66 \%$, PCOD in $13.3 \% .{ }^{17} 6 \%$ patients had pelvic inflammatory disease and $6 \%$ cases had normal study. Periera et al had observed $24.4 \%$ cases of endometriosis and $18.6 \%$ of pelvic inflammatory disease in her study. ${ }^{21}$ Shetty et al studied 50 patients and observed endometriosis in $24 \%$ patients, fibroid $36 \%$, pelvic inflammatory disease $6 \%$, mullerian anomalies $2 \%$ and $16 \%$ patients with normal findings. ${ }^{11}$ In our study $23 \%$ had endometriosis, $21.87 \%$ had pelvic inflammatory disease, $10 \%$ had tubal blockage, $9.37 \%$ with PCOS, while fibromyoma uterus and genital tuberculosis was reported in $4.68 \%$ each. $3.12 \%$ had hydrosalpinx and mullerian anomalies each while small number $(1.56 \%)$ had ovarian enlargement. The normal findings were present in $14.08 \%$ cases.

Bhatia et al studied 346 patients of infertility in India and observed bilateral spill in $58.4 \%$ patients, $17.3 \%$ with unilateral spill and $12.2 \%$ each with bilateral block and delayed spill. ${ }^{16}$ Kanal et al studied 40 patients of infertility in Jhansi, India and observed both tubes patent in $50 \%$ patients, bilateral blocked tubes in $40 \%$ patients and unilateral tubal blockage in $10 \%$ patients. ${ }^{6}$ Odusoga et al, conducted her study in 215 patients in Nigeria and observed bilateral tubal patency in $39.1 \%$ patients, bilateral block in $31.6 \%$ patients and unilateral block in $29.3 \%$ patients. $^{22}$ Periera et al studied 86 patients of infertility in Portugal. ${ }^{21}$ She observed both tubes patent in $53 \%$ patients, unilateral block in $20.5 \%$ patients and bilateral block in $20.5 \%$ patients.

Shetty et al, conducted her study in 50 patients of infertility in Manglore, India. ${ }^{11}$ She observed $56 \%$ patients with both tubes patent, $28 \%$ with unilateral block and $8 \%$ patients had bilateral blocked tubes. In our study bilateral tubes were patent in $53.12 \%$ patients, bilateral block in $18.75 \%$ patients, $10.93 \%$ patients with unilateral blockage. 


\section{CONCLUSION}

Prevalence of infertility is increasing, so is the awareness and treatment seeking behaviour. The present study assures that in evaluation and workup of primary infertility patients, after baseline non-invasive investigations, endometrial sampling and HSG, the diagnostic and operative laproscopy is an excellent tool for evaluation of tubal factor. Least expected conditions like endometriosis on clinical evaluation, can be diagnosed and treated with ease on laproscopy. Although tubal factor has been considered to be responsible for a large percentage of cases with female secondary infertility since decades, but in present study laproscopic evaluation confirmed tubal factor in $85.01 \%$ cases with female factor infertility. The diagnosis and operative procedure for treatment can be accomplished in same sitting. Thus, laproscopy with chromopertubation remain gold standard procedure for evaluation in female infertility and before planning further management for artificial reproductive technique.

\section{Funding: No funding sources}

Conflict of interest: None declared

Ethical approval: The study was approved by the Institutional Ethics Committee

\section{REFERENCES}

1. Dutta DC. Infertility. In: Textbook of Gynecology. Central. 2001;3:212-222.

2. Babar M, Shah WB, Mehmood KT. Diagnostic significance of laproscopy in infertility and identification of various unsuspected factors associated with infertility in females. J Pharm Sci Res. 2010;2(8):499-505.

3. Kumar P, Malhotra N. Infertility and Assisted Reproductive Technology. In: Jeffcoate,s Principle of Gynecology. New Delhi: Jaypee Brothers Medical Publishers Ltd; 2008;7:699-700.

4. Vayena E, Rowe PJ, Griffin PD. Current practices and controversies in assisted reproduction: report of a WHO meeting on "Medical, Ethical and Social aspects of Assisted Reproduction". World Health Organization; 2002:10-25.

5. Aubuchon M, Burney RO, Schust DJ, Yao M.W.M. Berek and Novaks Gynecology $15^{\text {th }}$ Ed. 1133-89.

6. Kanal P, Sharma S. Study of primary infertility in females by diagnostic laproscopy. Internet $\mathrm{J}$ Med Update. 2006;1(2):7-9.

7. Markar RS, Toth TL. The evaluation of infertility. Am J Clin Pathol. 2002;117(suppl 1):S95-S103.

8. Krysiewicz S. Infertility in women: diagnostic evaluation with hysterosapingography and other imaging techniques. AJR. 1992;159:253-61.
9. Sauer MV. Investigation of the female pelvis. J Reprod Med. 1993;38(4):269-76.

10. Fritz MA, Speroff L. Clinical Gynecologic. Endocrinol Infert. 2010;8:1177-85.

11. Shetty SK, Shetty H, Rai S. Laproscopic evaluation of tubal factor in cause of infertility. Int $\mathrm{J}$ Reprod Contracept Obstet Gynecol. 2013;2(3):410-3.

12. Nayak PK, Mahapatra PC, Mallick JJ, Swain S, Mitra S, Sahoo J. Role of diagnostic hysteronlaproscopy in the evaluation of infertility: A retrospective study of 30 patients. J Hum Reprod Sci. 2013;6(1):32-4.

13. Berker B, Mahadavi A, Shahmohamady B, Nezhat C. Role of laproscopic surgery in infertility. Middle East Fertility Society J. 2015;10(2):94-104.

14. Nalbanski B, Nikolov A, Novachkov V, Punevska $\mathrm{M}$. The importance of laproscopy in the diagnosis of tubal sterility. Akush Ginekol (Sofiia). 1990;29(6):25-30.

15. Shamim S, Farooq M, Shamim R. Diagnostic laproscopic findings in infertile patients in the Saudi population. Pak J Med Health Sci. 2010;4(4):560-3.

16. Bhatia R, Kaur S, Aggarwal S. Laprocopic Evaluation of Tubal Factor. Obs Gynae. 2002;7(9):538-41.

17. Haider G, Rani S, Talpur S, Zehra N, Munir A. Laproscopic evaluation of female infertility. J Ayub Med Coll Abbottabad. 2010;22(1):136-8.

18. Aziz N. Laproscopic evaluation of female factors in infertility. J Coll Physicians Surg Pak. 2010;20(10):649-52.

19. Butt ZUN, Khan GH. Study of infertility in females by laproscopy in remote area. J Rawalpindi Med College. 2009;13(2):89-91.

20. Tsuji I, Ami K, Miyazaki A, Hujinami N, Hoshiai H. Benefit of diagnostic laproscopy for patients with unexplained infertility and normal hysterosalpingography findings. Tohoku J Exp Med. 2009;219(1):39-42.

21. Pereira NR, Leite MH, Ribeiro RN, Passarinho RM, Castro MG, Matias SM. Laproscopy in the decision of treatment strategy for the infertile couple. Rev Bras Ginecol Obstet. 2010;32(9):441-6.

22. Odusoga OL, Oloyede OAO, Adewunmi AA, Fakoya TA. Experience with the laproscope in the evaluation of infertile women in Sagamu. Nigerian $\mathbf{J}$ Clin Pract. 2002;5(2):127-9.

Cite this article as: Bhatia R, Kaur P, Kaur G, Mor $\mathrm{S}$. Laproscopic evaluation in primary female infertility. Int J Reprod Contracept Obstet Gynecol 2019;8:4066-70. 